\title{
Bifurcate inferior pedicle mammoplasty in large ptotic breast for tumor located at the upper outer quadrant with skin involvement -a novel technique allowing good cosmetic outcome: case report
}

\author{
Simone Mele, Giuseppe Falco, Giulia Borgonovo, Fabio Castagnetti, Eugenio Cenini, Saverio Coiro, \\ Guglielmo Ferrari
}

Breast Surgery Unit, AUSL-IRCCS Reggio Emilia, Reggio Emilia, Italy

Correspondence to: Giuseppe Falco. Viale Risorgimento 80, 42124 Reggio Emilia, Italy. Email: Giuseppe.falco@ausl.re.it.

\begin{abstract}
Breast oncoplastic techniques followed by radiotherapy represent nowadays the standard of care for breast cancer treatment. For tumours located at the upper outer quadrant in patients with large and ptotic breasts, the use of level II breast reduction mammoplasty, allows large quadrantectomies without compromising the breast natural shape and reducing the breast volume to be irradiated. When the skin overlying the tumour in the upper outer quadrant is involved, the removal of the skin during mammoplasty could lead to an extreme reduction of the breast, resulting in a bad outcome. Different strategies have been adopted to avoid a poor cosmetic result including a $Z$ plastic or latissimus dorsi (LD) mini flap. At our institution we developed a new technique utilizing an inferior bifurcated pedicle mammoplasty with the preservation of a skin island for a patient with a residual tumour following chemotherapy involving the skin in the upper outer quadrant of the right breast. The patient did show no complications, with no delay for adjuvant radiotherapy treatment. Our method is a novel technique to treat malignancies in this location for patients with large and ptotic breasts when skin removal is indicated and it may represent an effective strategy to prevent excessive gland reduction, thus avoiding poor cosmetic result.
\end{abstract}

Keywords: Oncoplastic surgery; breast cancer; mammoplasty technique

Submitted Mar 13, 2020. Accepted for publication Jul 19, 2020.

doi: $10.21037 /$ gs-20-349

View this article at: http://dx.doi.org/10.21037/gs-20-349

\section{Introduction}

Oncoplastic techniques for breast cancer have reduced the number of mastectomies and allow to achieve good cosmetic results also in patients with large ptotic breasts. A quadrant per quadrant atlas was designed by Clough et al. developing different mammoplasty techniques according to the tumour location, allowing breast conservation following large excision (1). When less than $20 \%$ of breast volume is excised, a level I oncoplastic procedure is often adequate, permitting tumour excision by a single periareolar incision. Level II oncoplastic techniques allow to treat malignancies located at all different breast quadrants, when excision of volume is more of $20-50 \%$ and gland volume and size are appropriate, without compromising breast natural shape thus improving patient's self-image (1). For large tumour located at upper outer quadrant a racquet technique can be utilized. However, this lateral mammoplasty results in a long radial scar over the original tumour site with a periareolar extension. When removal of tumour overlying skin is needed, mammaplasty techniques represent an optimal choice to achieve surgical radicality and good cosmetic results. If skin to be removed belongs to upper outer quadrant, where large ptotic breasts require $\mathrm{T}$ mammoplasty, such method could lead to poor outcomes, meaning severe gland reduction. Cutress et al. have described a modification of the wise pattern in a series of 11 cases for tumor located in the upper outer or upper inner where a wise pattern would not be feasible, leaving a z scar on the breast (2). Latissimus dorsi (LD) mini flap also was described as a safe procedure to fill the space left 


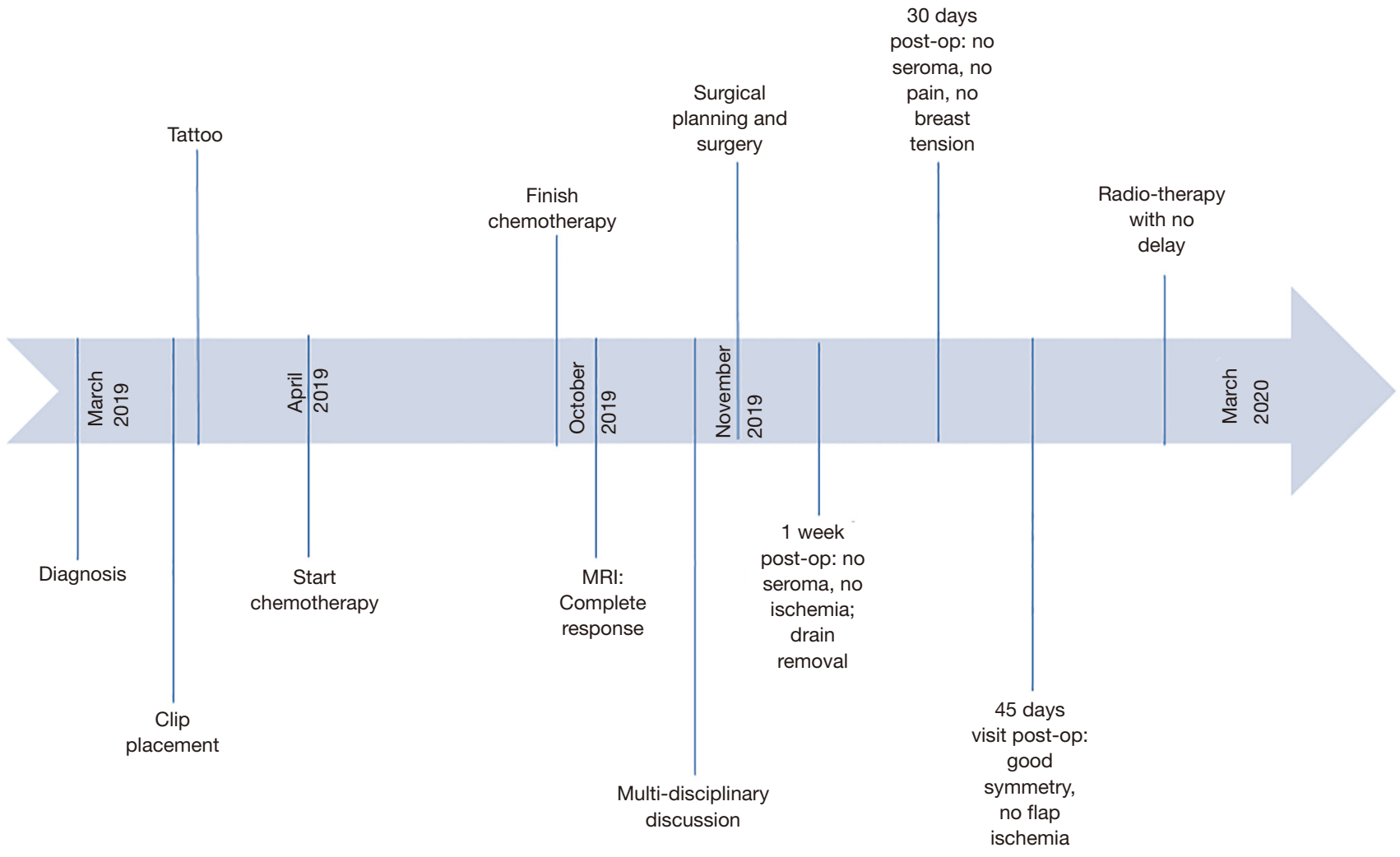

Figure 1 Timeline describing the neoadjuvant and surgical steps.

by the quadrantectomy (3). We describe a novel technique for treating breast tumours in patients with severe breast ptosis located at upper outer quadrant with the necessity to remove the overlying skin.

We present the following case in accordance with the CARE reporting checklist (available at http://dx.doi. org/10.21037/gs-20-349).

\section{Case presentation}

A 58-year-old woman with large ptotic breast (VII size with a $35.5 \mathrm{~cm}$ sternal notch-to-nipple distance) underwent neoadjuvant chemotherapy for $26 \mathrm{~mm} \mathrm{G} 3$ invasive ductal carcinoma (ER 95\%, PgR 20\%, Ki-67: 25\% HER2: pos) in the upper outer quadrant of the right breast, in association to skin retraction on April 2019. Before chemotherapy, tumour was clipped. Due to skin retraction, patient underwent skin tattoo at lesion. Followed 6 months of chemotherapy there was a complete radiological response, although skin appeared still retracted. Multidisciplinary team discussed the case and suggested quadrantectomy in addition to skin removal of previously tattooed area. Due to severe ptosis, right quadrantectomy through an inferior pedicle inverted $\mathrm{T}$ mammoplasty was chosen in addition to sentinel lymph-node biopsy and contralateral breast symmetrisation. After surgical planning, we decided to perform inferior bipedicled mammoplasty (by partially preserving skin at infero-lateral triangle) and to use it as coverage of removed skin at upper outer quadrant, to avoid excessive reduction of breast volume and addressed the patient for surgery on November 2019. Timeline is described in Figure 1.

In the pre-operative drawings sternal notch to nipple distance was moved from 35.5 to $23 \mathrm{~cm}$. Following Aufricht manoeuvre, tattooed skin overlying previous tumour remained out of inferior triangle (Figure 2) thus preventing radical reduction of breast volume. After de-epithelization of inferior pedicle at right breast, we carried out upper outer quadrantectomy including overlying skin. Specimen underwent pathological analysis, for margins involvement. Four amagnetic clips were located at quadrantectomy bed. Through the same incision, sentinel node was biopsied, 

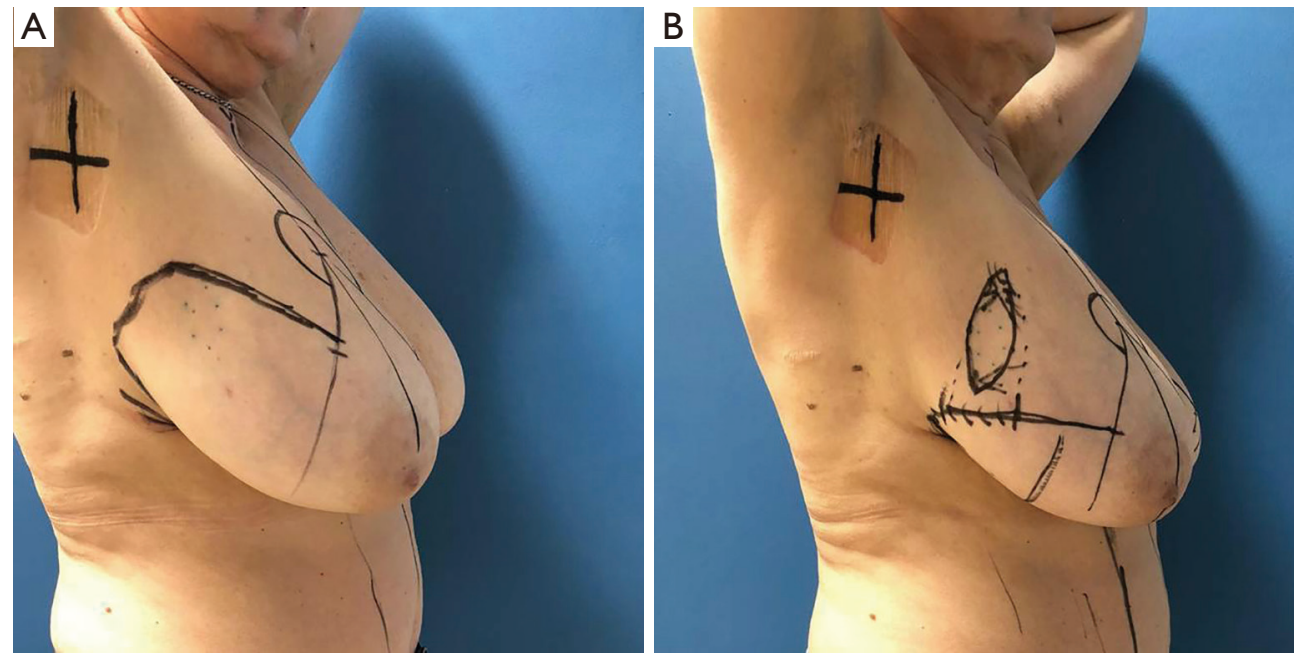

Figure 2 Pre-operative planning. (A) The quadrantectomy with overlying skin to remove is included in the $\mathrm{T}$ pattern. (B) The quadrantectomy with overlying skin to remove lays outside the $T$ pattern.

confirmed negative. At infero-external part of inferior triangle (infero-lateral pedicle) skin was not de-epithelized: it stayed attached to Wuringer septum and was partially separated from inferior medially located pedicle, leading to an inferior bi-pedicled pattern (Figure 3). Following glandular resection, which involved superior quadrants and infero-medial triangle, new breast was assembled, moving lateral pedicle at quadrantectomy bed to upper outer quadrant (Figure 3). We placed one $19 \mathrm{Fr}$ drainage per breast. Absorbable sutures were used for breast closure. Nipple areola complex was stabilized by $2 / 0$ Mersilene running suture, while skin underwent 4/0 intradermic absorbable suturing. Nipple areola complex skin was sutured with $5 / 0$ nylon. Patient was evaluated at 1 week (Figure 4), 1 month and 45 days (Figure 5). No complication occurred. Both nipple areola complex and infero-lateral flap did not show any ischemic signs. Drain was bilaterally removed after one week. Patient did not report any pain or breast tension. We did not experience any delays for adjuvant radiotherapy. The patient concluded adjuvant radiotherapy on March 2020 without complications.

All procedures performed in studies involving human participants were in accordance with the ethical standards of the institutional and/or national research committee(s) and with the Helsinki Declaration (as revised in 2013). Written informed consent was obtained from the patient for publication of this case report and any accompanying images.

\section{Discussion}

Therapeutic mammoplasty might allow most women to avoid mastectomy, with fewer complications than mastectomy and immediate reconstruction (4). Breast upper-outer quadrant represents the most common area where breast cancer occurs. Combination of breast conserving surgery (BCS) and plastic surgery techniques (oncoplastic breast surgery) represent a helpful surgical tool to achieve radical oncological excision, while preserving breast cosmesis $(5,6)$. Breast reduction techniques are being largely employed in the treatment of breast cancer for patients with large and ptotic breasts. In cancer affected patients having big glandular volumes, breast reduction can reduce radiotherapy side effects, due to a larger irradiation area, such as seroma, fat necrosis or cardiac toxicity. Different techniques rely on pedicle vascularity, which can be classified as superior, inferior, medial and lateral, as well as free nipple techniques. During reduction mammoplasty, Würinger's septum is usually preserved and many authors have described its role in maintaining blood supply and sensation of breast (7-9). Inferior pedicle breast reduction is a common approach which shows a short learning curve and can be easily applied (10). We used both traditional inferior pedicle technique and Würinger's septum, in order to create a new pedicle, which is lateral to inferior one. Use of both septum and inferior pedicle was already analysed by Kelahmetoglu et al. (11). Nevertheless our method 


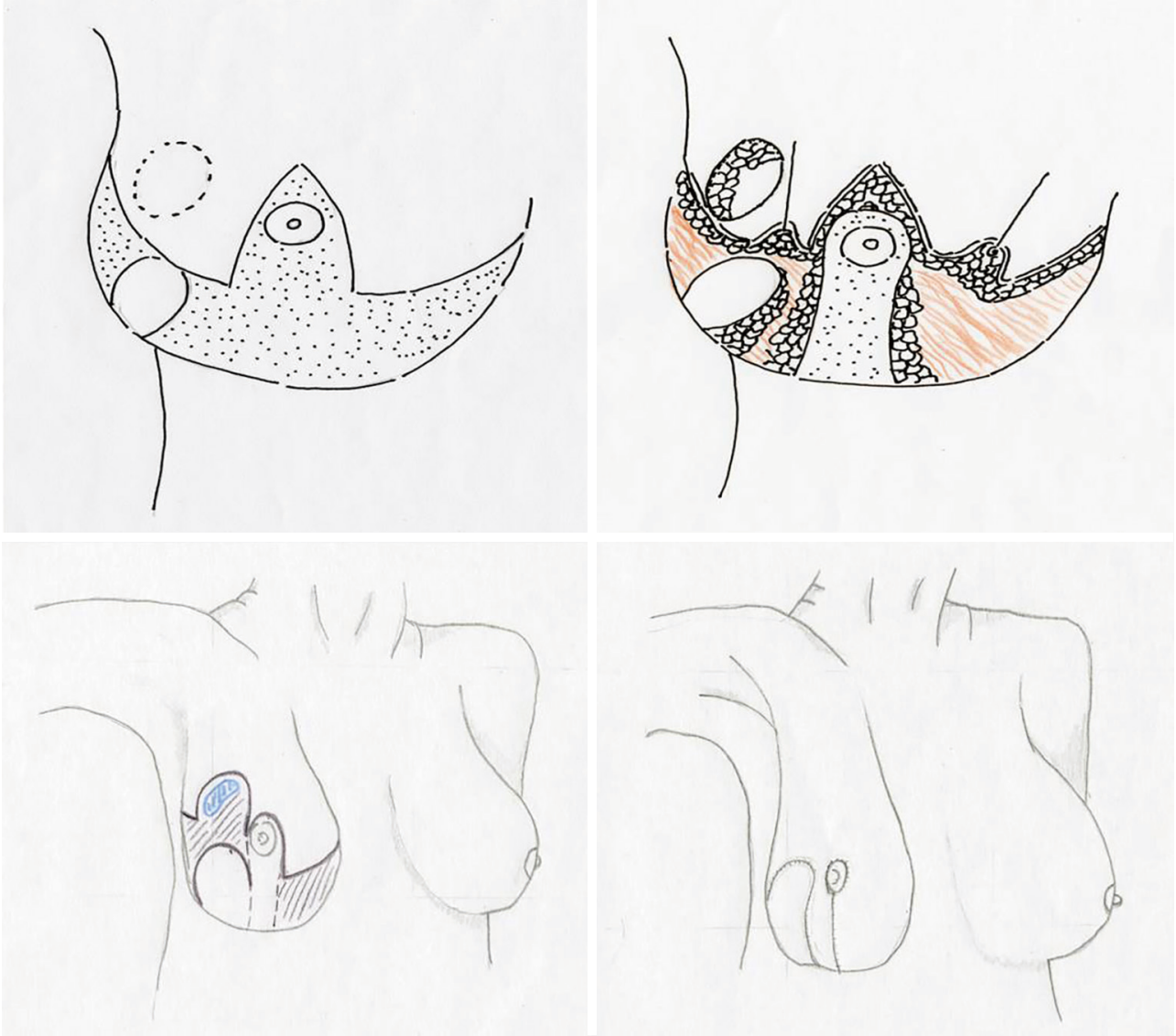

Figure 3 Intra-operative technique. Bifurcated inferior pedicle. Part of the infero-lateral triangle is not de-epithelized.

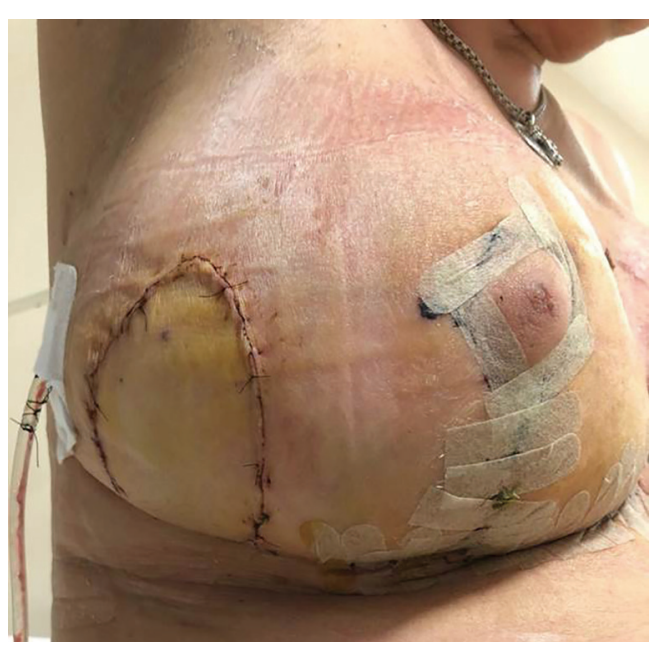

Figure 4 One-week post operation.

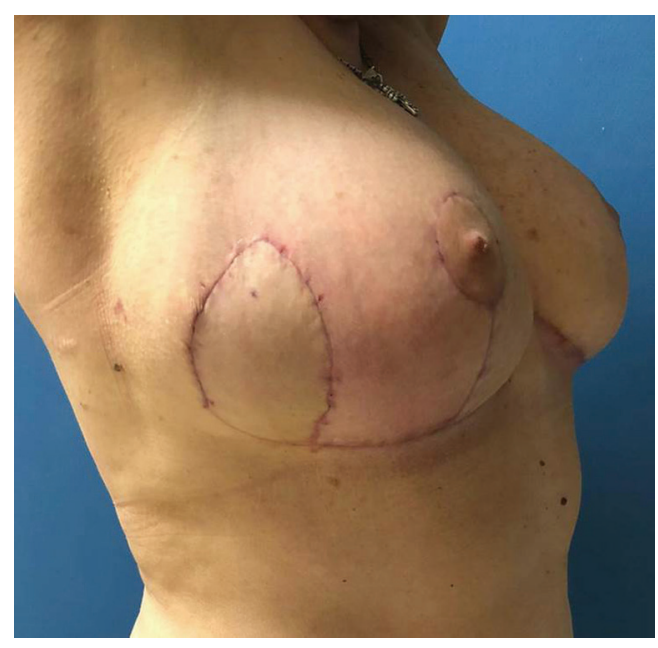

Figure 5 One-month post operation. 
represents the first attempt to integrate inferior bipedicled mammaplasty and preservation of overlying skin. Our method allows to radically reduce breast volume, when skin resection is needed and tumour is located in upper outer breast quadrant, though it is too far from $\mathrm{T}$ pattern incision. Furthermore, we observed no seroma or wound healing delay or minor complications at 1 week, 1 month and 45 days after surgery. This could be explained as a well vascularized vital tissues covered with skin carried in quadrantectomy area could improve scar healing and could reduce seroma production and fat necrosis. A limitation of this technique is represented by the number and the type of the scars and by the presence of a skin area of possible devascularization included between the vertical scar of the $T$ pattern and the medial scar of the pedicled flap. The latter area needs a careful attention during the drawings and the preparation of the flap avoiding an excessive proximity of the two scars.

\section{Acknowledgments}

We thank Dr. Claudio Pedrazzoli for the drawings and Dr. Daniela Masi for language revision.

Funding: None.

\section{Footnote}

Reporting Checklist: The authors have completed the CARE reporting checklist. Available at http://dx.doi.org/10.21037/ gs-20-349

Conflicts of Interest: All authors have completed the ICMJE uniform disclosure form (available at http://dx.doi. org/10.21037/gs-20-349). The authors have no conflicts of interest to declare.

Ethical Statement: The authors are accountable for all aspects of the work in ensuring that questions related to the accuracy or integrity of any part of the work are investigated and resolved. All procedures performed in studies involving human participants were in accordance with the ethical standards of the institutional and/or national research committee(s) and with the Helsinki Declaration (as revised in 2013). Written informed consent was obtained from the patient for publication of this Case report and any accompanying images.

Open Access Statement: This is an Open Access article distributed in accordance with the Creative Commons Attribution-NonCommercial-NoDerivs 4.0 International License (CC BY-NC-ND 4.0), which permits the noncommercial replication and distribution of the article with the strict proviso that no changes or edits are made and the original work is properly cited (including links to both the formal publication through the relevant DOI and the license). See: https://creativecommons.org/licenses/by-nc-nd/4.0/.

\section{References}

1. Clough KB, Kaufman GJ, Nos C, et al. Improving breast cancer surgery: a classification and quadrant per quadrant atlas for oncoplastic surgery. Ann Surg Oncol 2010;17:1375-91.

2. Cutress RI, Simoes T, Gill J, et al. Modification of the Wise pattern breast reduction for oncological mammaplasty of upper outer and upper inner quadrant breast tumours: a technical note and case series. J Plast Reconstr Aesthet Surg 2013;66:e31-6.

3. Mele S, Wright D, Paramanathan N, et al. Long-term effect of oncoplastic breast-conserving surgery using latissimus dorsi miniflaps on mammographic surveillance and the detection of local recurrence. J Plast Reconstr Aesthet Surg 2017;70:1203-9.

4. Potter S, Trickey A, Rattay T, et al. Therapeutic mammaplasty is a safe and effective alternative to mastectomy with or without immediate breast reconstruction. Br J Surg 2020;107:832-44.

5. Bordoni $\mathrm{D}$, Cadenelli $\mathrm{P}$, Ornelli $\mathrm{M}$, et al. The axillary flap in oncoplastic resection of breast cancers located in the upper-outer quadrants: a new surgical technique. BMC Surg 2019;18:21.

6. Clough KB, Lewis JS, Couturaud B, et al. Oncoplastic techniques allow extensive resections for breast-conserving therapy of breast carcinomas. Ann Surg 2003;237:26-34.

7. Hamdi M, Van Landuyt K, Tonnard P, et al. Septum-based mammaplasty: a surgical technique based on Würinger's septum for breast reduction. Plast Reconstr Surg 2009;123:443-54.

8. Bayramiçli M. The central pillar technique: a new septumbased pedicle design for reduction mammaplasty. Aesthet Surg J 2012;32:578-90.

9. Ryssel H, Germann G, Reichenberger R. Craniomedial pedicled mammaplasty based on Würinger's horizontal septum. Aesthetic Plast Surg 2010;34:494-501.

10. Koger KE, Sunde D, Press BH, et al. Reduction mammaplasty for gigantomastia using inferiorly based 
pedicle and free nipple transplantation. Ann Plast Surg 1994;33:561-4.

11. Kelahmetoglu O, Firinciogullari R, Yagmur C, et al. Combination of Würinger's Horizontal Septum and

Cite this article as: Mele S, Falco G, Borgonovo G, Castagnetti F, Cenini E, Coiro S, Ferrari G. Bifurcate inferior pedicle mammoplasty in large ptotic breast for tumor located at the upper outer quadrant with skin involvement-a novel technique allowing good cosmetic outcome: case report. Gland Surg 2020;9(5):1590-1595. doi: 10.21037/gs-20-349
Inferior Pedicle Techniques to Increase Nipple-Areolar Complex Viability During Breast Reduction Surgery. Aesthetic Plast Surg 2017;41:1311-7. 